\title{
Implementação de um sistema Collaborative Planning, Forecasting, and Replenishment em uma grande rede de fast food por meio de um prestador de serviços logísticos
}

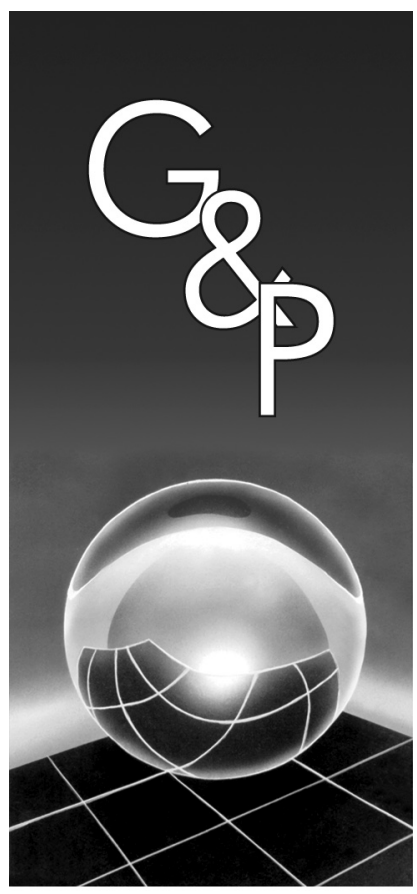

\author{
Mauro Vivaldini \\ Fernando Bernardi de Souza \\ Silvio Roberto Ignácio Pires
}

Resumo

A gestão colaborativa é, atualmente, um elemento-chave no contexto da gestão da cadeia de suprimentos. Neste artigo, o tema é abordado mediante a análise de um caso real, em que uma grande rede mundial de fast-food e seu prestador de serviço logístico (PSL) trabalharam conjuntamente no Brasil em um projeto-piloto para a implementação de um collaborative planning, forecasting, and replenishment (CPFR). O trabalho faz uso de uma metodologia de pesquisa-ação e apresenta as principais variáveis que influenciaram o projeto, abordando os processos necessários para a implementação e os pontos que favorecem o CPFR. Com base no caso estudado, o trabalho apresenta um conjunto de propostas sobre o papel dos agentes da cadeia em projetos dessa natureza. A gestão da cadeia de suprimentos por intermédio da coordenação direta de um PSL também permite demonstrar as possibilidades e dificuldades desse sistema, contribuindo com a visão colaborativa na cadeia de suprimentos a partir da relação entre seus agentes.

Palavras-chave: Gestão da cadeia de suprimentos. Reposição. Previsão e planejamento colaborativo (CPFR). Prestador de serviços logísticos (PSL).

\section{Introdução}

A gestão da demanda e a formação de um correto pedido de compra são processos relativamente complexos na gestão da cadeia de suprimentos, geralmente ocasionados pela falta de mecanismos que permitam visibilidade dos estoques e das vendas. Encontrando-se meios para geração destas informações, todos os participantes da cadeia de suprimentos (CS) tendem a ganhar se elas estiverem disponíveis (MENTZER et al., 2004). Neste sentido, este trabalho entende a utilização do CPFR (collaborative planning, forecasting, and replenishment - reposição, previsão e planejamento colaborativo) como uma prática intimamente atrelada à gestão do relacionamento da CS, em especial, a partir da administração da demanda e dos pedidos de compra.

Neste contexto, este estudo trata do desenvolvimento e implementação de um sistema CPFR de uma grande rede mundial de fast-food por meio de seu prestador de serviços logísticos (PSL).

A relevância maior do estudo consiste no fato de se trabalhar com um caso prático, diferentemente da literatura atual que tem abordado o tema de forma muito mais teórica, além do fator inovador de se ter um PSL na coordenação dos processos de implementação.

O desenvolvimento dos serviços executados por PSL vem ganhando abrangência nos últimos anos, e seu papel na gestão da cadeia de suprimentos (supply chain management-SCM) vem adquirindo diferentes dimensões em função do escopo de atividades envolvidas. Nos últimos anos, têm surgido novas configurações de PSL, como o de integradores logísticos ou 4PL (fourth providers logistics), com um papel combinado de gestão e de operação das necessidades logísticas da CS (SAHAY, 2003; LIEB; BENTZ, 2005; MENTZER, 2005).

Pelo fato de ainda existirem muito poucos casos que relatam experiências sobre o tema, este estudo busca contribuir para o entendimento do processo de implementação do CPFR, demonstrando os processos operacionais que compõem a SCM colaborativa, as dificuldades identificadas e aspectos relevantes. Além disso, o artigo apresenta o CPFR num seguimento diferenciado, fora dos casos comumente descritos em redes de supermercados. 


\section{Metodologia de pesquisa}

Os autores deste artigo fizeram parte de um grupo de implementação de um projeto-piloto para um sistema de controle e planejamento da demanda, do estoque nos restaurantes, nos fornecedores e no operador logístico, com o propósito principal de evitar desabastecimentos. Assim, por se tratar de um estudo em que os autores fizeram parte da equipe, sendo a pesquisa simultânea com os fatos e questões que surgiram do trabalho do grupo (COUGHAN; COGHLAN, 2002), a metodologia utilizada foi a da pesquisa-ação. Esta metodologia favoreceu a busca de dados pertinentes, facilitou entrevistas e o acesso às informações relevantes do caso, além de ter permitido a interação direta dos autores com os agentes participantes do processo. Os trabalhos começaram em março de 2004 e encerraram-se em agosto de 2005. Esti- veram diretamente envolvidos no projeto 9 profissionais corporativos da rede de fast-food, 12 representando os fornecedores, 6 do PSL e 30 funcionários dos restaurantes da rede de fast-food.

A Figura 1 ilustra a estrutura da pesquisa realizada.

O estudo analisou o projeto de implementação de CPFR mediante três tópicos principais:

a) Teoria e prática: teve como objetivo estabelecer o entendimento teórico atual sobre os temas gestão da demanda, CPFR e relacionamento, bem como a visão prática de como atuam os agentes na CS estudada;

b) Pesquisa-ação: focou o processo prático de implementação, apresentando os ciclos de trabalhos, problemas, pontos a serem desenvolvidos no projeto, resultados, e o processo de implementação

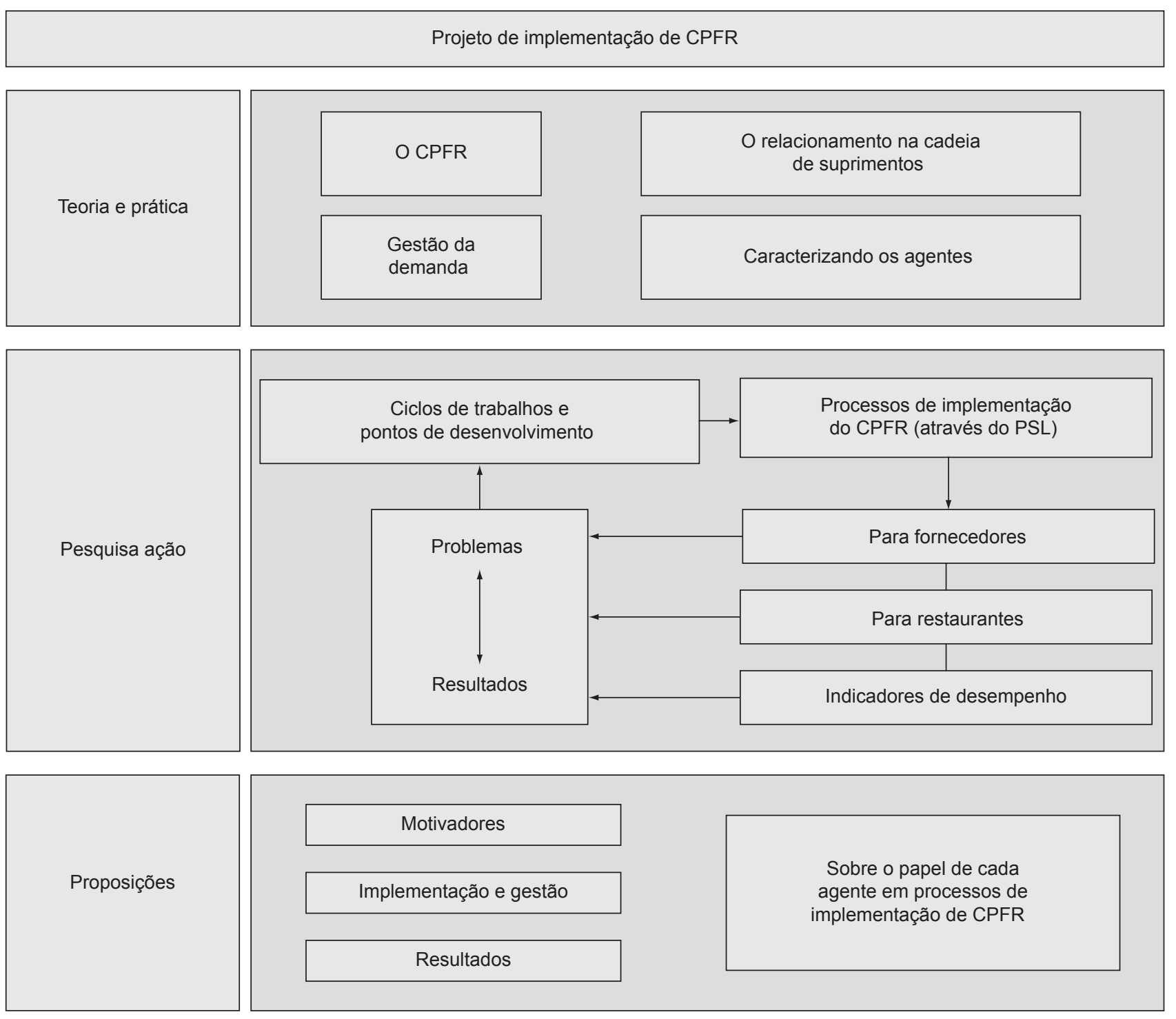

Figura 1. Estrutura do projeto de pesquisa. 
e formação de indicadores com fornecedores e restaurantes; e

c) Proposições: descrita a prática do processo de implementação, o estudo trabalhou um conjunto de proposições baseadas na pesquisa-ação, na intenção de orientar o papel dos agentes em projetos dessa natureza.

\section{Teoria e prática}

Geralmente, a gestão da demanda é abordada pela literatura na área como um dos fatores de maior dificuldade para a administração da CS, pois sua gestão depende muito do envolvimento dos agentes da cadeia. Por sua vez, o CPFR tem se apresentado com um sistema contemporâneo capaz de responder a essa questão. No entanto, o desempenho do CPFR depende, fundamentalmente, do relacionamento existente na CS e da postura de seus agentes.

Esses quatro pontos identificados (gestão da demanda, CPFR, relacionamento e como atuam os agentes) são apresentados a seguir, com o propósito de fundamentar conceitualmente a pesquisa.

\subsection{Gestão da demanda e pedidos de compra}

A gestão da demanda torna-se um problema pela dificuldade que se tem em controlar os extremos (picos ou quedas nas vendas, que ocorrem em diferentes proporções e frequiências) e estabelecer o pedido de reposição que melhor reflita essas oscilações. Como conseqüência, a ruptura causada na cadeia por falta de produto reflete diretamente nos custos.

Para evitar essas ocorrências, as empresas tendem a elevar o nível de estoque na cadeia, procurando com isso estar preparada para atender a pedidos urgentes gerados em cima da hora. O resultado disso são custos desnecessários a todos os agentes da cadeia, resultando em ganhos reduzidos por pedido.

Para Mentzer e Moon (2004), uma cultura colaborativa entre os agentes da cadeia é essencial para uma boa gestão da demanda. Para esses autores, a gestão da demanda é parte da SCM e deve ser coordenada pelos seus agentes. Geralmente, a área de marketing cria a demanda, mas tende a não criar um plano para ela, diferente do que ocorre com as previsões feitas para outras atividades da empresa.

Os referidos autores chamam a atenção para que não haja confusão entre fazer "previsões" com "planejar a demanda", o que seria um erro. A intenção passa a ser, então, estar mais próximo da demanda do cliente final. A dimensão desse plano deve abranger previsões para todas as áreas funcionais envolvidas no processo produtivo, como produção, abastecimento, logística, etc. Assim, acreditam que um sistema de informação bem coorde- nado entre os agentes e internamente com todas as áreas relacionadas com o abastecimento, a partir de um plano de vendas e operações, pode ampliar o fluxo de abastecimento baseado em um único sentido para os dois sentidos (montante e jusante).

Por outro lado, a SCM busca alcançar maior satisfação dos requerimentos do consumidor mediante processo de integração comprador-fornecedor. Esta integração é tipicamente alcançada pela troca de informação e é, subseqüentemente, composta pelo estabelecimento de um processo que alinhe a identificação física da necessidade de reposição com uma resposta em tempo real (CHRISTOPHER; TOWILL, 2001).

\subsection{Collaborative planning, forecasting, and replenishment}

Vickery et al. (2003) afirmam que uma CS pode ser estrategicamente administrada como uma entidade independente, ou como um sistema individual fragmentado em seguimentos ou subsistemas. Isto requer a integração das atividades, funções e sistemas pela cadeia. Uma estratégia integrada da CS reconhece que o processo comercial integrado cria valor para as empresas clientes. Para os autores, a utilização de tecnologia de informação e comunicação (TIC) é um forte capacitador para o processo de integração.

Também, Rutner et al. (2003) observam que o avanço do processo de comércio eletrônico tem colaborado para os processos de integração das operações logísticas, melhorando o acesso e as conexões entre os diversos tipos de informação.

Considerando a importância tecnológica para a CS, os principais sistemas que contribuem para o processo de gestão colaborativa por intermédio da integração de dados e informações são:

a) EDI (electronic data interchange): tem como finalidade a troca eletrônica de dados entre computadores de empresas que se relacionam comercialmente ou estão envolvidas na cadeia. Sua utilização tende a manter a operação mais coordenada com supridores e clientes;

b) VMI (vendor management inventory): neste sistema, o fornecedor tem a responsabilidade de gerenciar seu estoque no cliente, incluindo o processo de reposição, podendo, com isso, melhorar as operações de controle de estoque, produção e distribuição (PIRES, 2004; DISNEY; TOWILL, 2003, DISNEY et al. 2003);

c) ECR (efficient consumer response): combina duas inovações conceituais, como reposição eficiente de estoque e gestão de categorias (HOLMSTROM et al. 2002). Sua implementação quase sempre requer investimento adicional em TIC, como código de barras, scanner, EDI, etc. A lógica desse sistema 
baseia-se no ponto de reposição do estoque e no JIT, dado que a demanda e/ou a reposição do item é sempre puxada pelo ponto de consumo (PIRES, 2004; WANKE; ZINN, 2004; BONET; PACHÉ 2005);

d) $\mathrm{CR}$ (continuous replenishment): o $\mathrm{CR}$ pode ser considerado um estágio além do VMI, pois a gestão de estoque passa a ser feita com base na previsão de vendas e na demanda histórica, e não mais apenas nas variações do nível de estoque do ponto-devenda; e

e) CPFR (collaborative planning, forecasting and replenishment): tem por o objetivo, ajudar as empresas a administrar e compartilhar informações conjuntamente. Sua intenção é equilibrar a relação na cadeia mediante controle de estoque em todos os elos.

O CPFR visa facilitar a colaboração entre as empresas, principalmente no tocante à previsão de vendas. Seu sucesso dependerá de questões básicas, como a existência de processos internos às empresas bem estruturados e operacionalizados, bem como o estabelecimento de uma sólida relação entre as empresas parceiras (PIRES, 2004).

Este estudo aborda a utilização do CPFR intimamente atrelada à gestão do relacionamento da CS. Se não houver maturidade e envolvimento das empresas, sua utilização pouco contribuirá para os resultados. Portanto, o estudo não entende o CPFR simplesmente como uma troca de informação ou compartilhamento de dados, mas, como um importante sistema para a SCM.

Um dos mecanismos que facilitam o processo de implementação do CPFR é o aproveitamento de práticas de gestão já em uso, como VMI, ECR e outras (HOLMSTROM et al. 2002), bem como ter uma infraestrutura de TIC que facilite o processo.

Um ponto interessante lembrado por Fliedner (2003) é o fato de implementações do CPFR estarem mais presente em mercados mais competitivos e com demanda mais volátil, como, por exemplo, no seguimento de alimentos e objetos da moda.

\subsection{O relacionamento colaborativo na cadeia de suprimentos}

A colaboração entre os agentes de uma CS é analisada em uma pesquisa recente de Porier e Quinn (2006), que destaca esta intenção como meta das empresas. Apesar de esta visão estar presente em muitas empresas, os autores apontam que a verdadeira colaboração ainda é um conceito muito difícil de ser aceito, especialmente quanto à divisão de informações internas com os parceiros externos. Entretanto, a maioria das empresas reconhece a necessidade de trabalhar em colaboração com seus supridores e clientes. Neste caminho, uma das forças trabalhadas pelas empresas tem sido o investimento em ferramentas tecnológicas que apóiam o relacionamento, como o CPFR.

Golic e Mentzer (2006) relatam que os diferentes tipos de relacionamentos entre empresas surgem por diferentes situações, cada relacionamento requer diferentes tipos e graus de investimentos e produz diferentes resultados. Muitas empresas ficam apreensivas em investir tempo e recursos na melhoria do relacionamento porque raramente vêem retorno financeiro sobre o investimento. Para os autores, isto, na prática, não reflete a realidade, pois um alto valor é percebido com a melhora do relacionamento, além do que, as empresas podem obter resultados positivos se, pacientemente, desenvolverem o relacionamento colaborativo.

Min et al. (2005) propõem uma estrutura de relacionamento colaborativo apoiado em 3 pilares:

a) Antecedentes: posiciona as empresas com relação aos interesses estratégicos, ao alinhamento interno, à orientação que possuem para o relacionamento, à disponibilidade de investir no relacionamento e a ter um fluxo livre de informação e comunicação. Isso prepara as empresas para caminhar para o passo seguinte;

b) Colaboração: nesta etapa, a empresa deve trabalhar compartilhando informações, planejando, resolvendo problemas e medindo desempenho em conjunto com seus parceiros, na intenção de alavancar recursos e habilidades para melhoria dos negócios; e

c) Conseqüências: a partir de um posicionamento colaborativo, a empresa deve ter maior eficiência e eficácia, melhorar a rentabilidade, além de continuamente poder reforçar e expandir a relação entre os parceiros. Neste ponto, caso haja situações que não reflitam este avanço, retorna-se ao passo anterior, o qual trabalha a questão da relação entre parceiros.

Ainda nesta linha, Min et al. (2005) afirmam que, para organizar os processos colaborativos, as empresas devem trabalhar juntas no planejamento e na implementação. Adicionalmente, devem trabalhar no monitoramento das atividades que integram as operações entre as empresas com um foco comum a todas, sendo importante dividir e manter as informações confidencialmente. Também, as empresas parceiras devem trabalhar as informações de forma a ajudar a operação do negócio. Além disso, o processo de colaboração deve ser formalizado, detalhando as métricas de desempenho e os objetivos. Assim, o processo de colaboração criará um novo ambiente e uma nova cultura de operações. Apesar disso, os autores apontam que os processos de colaboração são tipicamente feitos para atender os clientes, pois são eles que geralmente iniciam os esforços para isso e tendem a se beneficiar mais do que os outros neste processo. 


\subsection{Caracterizando os agentes da cadeia de suprimentos}

Durante sua trajetória, a rede mundial de fast-food estudada desenvolveu uma relação compromissada com seus fornecedores, compartilhando missões, objetivos, crenças e valores em todos os locais do planeta onde atua. Essa posição claramente fortaleceu o comportamento colaborativo. Em contrapartida, deu à maioria dos fornecedores exclusividade no abastecimento dos restaurantes.

Nessa relação, o papel de cada agente participante da CS pode ser resumido em:

a) Rede de fast-food: responsável pela operação dos restaurantes, pelo estabelecimento de promoções e propagandas, pela seleção de fornecedores, preços e produtos, pelo desenvolvimento de novos produtos, pela elaboração de planos estratégicos para o negócio, pela avaliação e padronização dos processos e pela resolução de conflitos na cadeia;

b) PSL: responsável pela gestão de compras e estoques, pelo atendimento aos restaurantes, pela armazenagem, distribuição e transporte, pelas transferências a outros centros de distribuição no País, pela gestão financeira da cadeia, pelo planejamento logístico, pelo planejamento fiscal, pelo serviço de campo e pela coordenação das operações de abastecimento na cadeia; e

c) Fornecedores: responsável pela manufatura com qualidade assegurada, pelo desenvolvimento de novos produtos (em conjunto com a rede de fast-food) e pela gestão da cadeia a montante (inbound).

A Figura 2 ilustra as relações entre as partes componentes da CS estudada.

Destaca-se que essa estrutura da CS da rede de fast-food, com o PSL coordenando o abastecimento e o trânsito de informações entre os agentes, favorece a implantação de um programa de CPFR, pois alguns obstáculos, segundo Fliedner (2003), como informações não compartilhadas e sem padrão entre os agentes, ausência de prática de previsão e medo de confronto na relação, podem ser considerados superados entre os integrantes desta cadeia.

Segundo uma pesquisa realizada por Danese et al. (2004), o caminho encontrado para implantação de processos de colaboração em cadeias de suprimentos é trabalhar com força-tarefa, comitês de padronização e

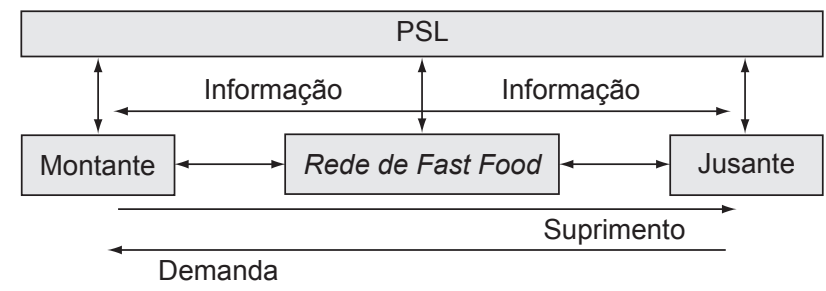

Figura 2. Visão da cadeia de suprimentos estudada. integração gerencial. No caso, o ciclo de relação existente na cadeia estudada permite essa aplicação para implementação de novos métodos de gestão.

\section{Implementação do CPFR mediante um PSL em uma rede de fast-food}

Este tópico destaca os ciclos e os pontos que foram considerados necessários para a implementação do CPFR no caso estudado, como a organização e os ciclos de trabalho adotados pelos agentes da CS, o processo de implementação nos fornecedores e restaurantes, bem como os principais problemas e resultados obtidos durante o processo.

\subsection{Organização e ciclos de trabalhos}

O processo de implementação do CPFR nasceu da necessidade da rede de fast-food resolver um problema enfrentado pelos gestores de restaurantes: deles terem mais tempo para a operação, aliviando a carga de trabalho administrativa, principalmente das atividades relacionadas ao abastecimento e controle de estoque.

Uma das sugestões para se trabalhar na melhoria do abastecimento do restaurante foi utilizar o PSL nessa gestão. A razão da escolha do PSL foi devida ao fato dele estar mais próximo de todos os agentes da CS, bem como por já ter um sistema de informação e coleta de pedido integrado com todos os restaurantes, adotar alguns mecanismos de repasse de informação aos fornecedores em tempo real e ter ligação direta com a matriz administrativa da rede de fast-food, servindo como agente facilitador da relação e detentor das informações.

A partir dessa escolha, criou-se um grupo para a discussão do tema e construção do projeto - chamado de grupo mestre. Este grupo passou a ser o direcionador de todas as ações estratégicas do projeto. Os trabalhos começaram em março de 2004 e a primeira etapa do projeto-piloto encerrou-se em agosto de 2005. Com o escopo inicial do projeto definido, foram montadas equipes de trabalho com responsabilidades definidas. Essas equipes, voltadas à implantação, continham elementos do grupo mestre com apoio de profissionais das áreas envolvidas no desenvolvimento.

\subsubsection{Ciclos a serem trabalhados}

As primeiras reuniões do grupo mestre procuraram definir os pontos a serem desenvolvidos pela equipe e alinhar o foco e os objetivos do trabalho, ou seja, (1) verificar a viabilidade de integrar a CS por intermédio do PSL e (2) reduzir a participação dos gestores de restaurantes em processos administrativos relacionados ao controle de estoque e abastecimento.

O Quadro 1 resume os principais elementos e as prioridades definidas para serem desenvolvidas pelas equipes. 
Quadro 1. Elementos do desenvolvimento do CPFR da cadeia.

\begin{tabular}{|c|c|c|c|c|c|c|c|c|}
\hline $\begin{array}{l}\text { Projeção de volume } \\
\text { para fornecedores }\end{array}$ & I & M & $\begin{array}{c}\text { Recomendação de pedido } \\
\text { ao restaurante } \\
\end{array}$ & $\mathbf{I}$ & $\mathbf{M}$ & Medidas e indicadores & I & $\mathbf{M}$ \\
\hline Administração de itens em estoque & 3 & B & $\begin{array}{l}\text { Gestão de estoque do restaurante } \\
\text { (cadastro de itens) }\end{array}$ & 1 & $\mathrm{~B}$ & $\begin{array}{l}\text { Análise de desempenho do } \\
\text { restaurante }\end{array}$ & 1 & B \\
\hline $\begin{array}{l}\text { Conectividade e alimentação de } \\
\text { dados com os CDs }\end{array}$ & 2 & B & $\begin{array}{l}\text { Gestão de estoque do restaurante } \\
\text { (administração do estoque) }\end{array}$ & 1 & B & $\begin{array}{l}\text { Análise de desempenho das } \\
\text { promoções }\end{array}$ & 1 & B \\
\hline $\begin{array}{l}\text { Visibilidade do estoque nos CDs do } \\
\text { PSL }\end{array}$ & 1 & A & $\begin{array}{l}\text { Administração de itens do menu do } \\
\text { restaurante }\end{array}$ & 3 & $\mathrm{~B}$ & Performance dos CDs & 1 & $\mathrm{C}$ \\
\hline Gerenciamento de estoques limitados & 3 & A & $\begin{array}{l}\text { Conectividade e coleta de dados nos } \\
\text { restaurantes }\end{array}$ & 1 & B & Performance de transporte & 1 & $\mathrm{C}$ \\
\hline Projeção de demanda dos CDs & 1 & $\mathrm{~B}$ & Impacto de promoções e campanhas & 1 & A & Performance dos fornecedores & 1 & B \\
\hline Compras centralizadas dos CDs & 1 & $\mathrm{C}$ & $\begin{array}{l}\text { Projeção de demanda dos restau- } \\
\text { rantes }\end{array}$ & 1 & B & $\begin{array}{l}\text { Peformance global da cadeia } \\
\text { de suprimentos }\end{array}$ & 1 & A \\
\hline Otimização da carga dos fornecedores & 1 & $\mathrm{C}$ & Gestão de estoques limitados & 3 & A & & & \\
\hline Planejamento de compra nos CDs & 1 & $\mathrm{C}$ & $\begin{array}{l}\text { Abastecimento dos restaurantes } \\
\text { (planejamento) }\end{array}$ & 1 & A & & & \\
\hline Troca de arquivos com os fornecedores & 1 & B & $\begin{array}{l}\text { Abastecimento dos restaurantes } \\
\text { (pedido recomendado) }\end{array}$ & 1 & A & & & \\
\hline \multirow[t]{2}{*}{ Otimização da rede } & \multirow[t]{2}{*}{3} & \multirow[t]{2}{*}{ A } & Otimização de transporte & 1 & $\mathrm{C}$ & & & \\
\hline & & & $\begin{array}{l}\text { Gestão centralizada de pedidos dos } \\
\text { restaurantes }\end{array}$ & 1 & A & & & \\
\hline Itenc definidos nara decenylyime & & & & & & & & \\
\hline
\end{tabular}

A idéia foi evitar trabalhos em processos já estabelecidos ou mesmo consolidados, ou aqueles que pouco contribuiriam para os objetivos do projeto.

\subsection{O processo de implementação}

Nos próximos tópicos, são estabelecidas as ações operacionais na implementação dos pontos de trabalho definidos no Quadro 1.

\subsubsection{Projeção de volume aos fornecedores}

Esta etapa do processo de implementação foi a que mais facilmente se ajustou às necessidades dos agentes participantes, com rápida solução dos ciclos de trabalho. Isto ocorreu por haver entre eles maturidade na relação e no sistema de transmissão de dados, bem como por ser o estoque centralizado nos centros de distribuição do PSL, que recebe os pedidos dos restaurantes e faz o despacho. Assim, a transmissão dos dados concentra-se no PSL, com ajustes, quando necessários, nos fornecedores.

Coube a cada fornecedor adequar o processo de integração com seu ERP (enterprise resource planning), apoiado pela área de tecnologia da informação do PSL. Neste processo, os fornecedores foram divididos em dois grupos, em função do tipo de produto.
O grupo um incluiu, inicialmente, três fornecedores, por serem estrategicamente importantes para o abastecimento do restaurante ou por fornecerem itens fundamentais (presente em $80 \%$ dos pratos e sanduíches) para a operação. Os fornecedores utilizariam as informações via EDI da venda efetiva, com integração completa ao ERP de cada empresa, gerando internamente todos os inputs necessários para agilizar o processo produtivo e o abastecimento do PSL. Nesse grupo, praticamente só se produz o que vende e a transferência física ao PSL é imediata para que se possa fazer o despacho ao restaurante. Tem-se nesta operação o equilíbrio entre estoque e demanda, ou seja, o nível necessário para atender aos pedidos e não desabastecer o ponto-de-venda..

Para o segundo grupo, o PSL criou um portal de relacionamento na internet direcionado exclusivamente aos fornecedores da rede de fast-food que, por intermédio de uma senha de acesso, pode visualizar o estoque em tempo real nos centros de distribuição (CDs), a necessidade de reposição imediata e a projeção da demanda para 6 semanas. Este mecanismo é gerenciado pela área de programação de estoque do PSL, que administra o volume de acordo com o tipo de produto, distância do fornecedor, confiabilidade de entrega, etc. 
A visão da venda do item no ponto-de-venda fica à disposição do fornecedor no portal. Neste caso, a informação gerada no ponto-de-venda é traduzida para a linguagem do fornecedor com base na receita dos produtos, gerando o consumo do item. Apesar disso, a confirmação de pedido e a programação para produção efetiva deve ser baseada na informação do PSL. Ou seja, a informação da venda real deve ser entendida como uma orientação ao fornecedor.

\subsubsection{Recomendação de pedido ao restaurante}

Nesta etapa, na qual a responsabilidade pela execução das atividades envolve um número maior de participantes, o trabalho apresentou muito mais variáveis e inconformidades. Provavelmente, a razão disso se deveu à inexperiência dos participantes e gestores dos restaurantes em trabalhar e entender o sistema integrado, segundo o qual a venda no caixa/balcão tem relação direta com o estoque e o abastecimento.

Vale destacar que a referência de dados, históricos, inputs de informação e validação de pedidos vem do ponto-de-venda, ou seja, do restaurante. Todo o sistema de gestão opera e cria sugestão do pedido de acordo com estas referências, exceto nas promoções, em que a área de marketing define a metodologia a ser adotada para cada campanha.

Testes iniciais foram realizados em um restaurante. Posteriormente, foram feitas algumas correções de rumo e passou-se para três restaurantes. Finalmente, com uma visão melhor definida do projeto, passou-se para mais 11 , totalizando um grupo de 15 , todos em uma mesma região (por facilidade de gestão).

\subsubsection{Gestão do estoque}

Uma boa gestão de estoque pode ser considerada o princípio básico para se gerar informações confiáveis a todos no sistema. Nos restaurantes da rede de fast-food, apesar de adotarem uma padronização dos processos de gestão do estoque, existiam particularidades, pertinentes a cada ponto-de-venda, irrelevantes num processo menos informatizado, porém inconsistentes num processo totalmente integrado. Quando da transmissão da informação para o sistema de dados, todas as inconsistências devem ser resolvidas para que a linguagem entre todos os envolvidos passe a ser comum.

Nesta etapa, o objetivo foi estabelecer uma linguagem única em toda a cadeia para os itens em estoque, bem como ter o estoque do restaurante em tempo real. Para isso, as ações implementadas foram:

a) unificação dos códigos e nomes dos produtos, utilizados pelo ponto-de-venda, em toda a cadeia;

b) padronização das unidades de transação, exceto na venda ao consumidor final. Foi definido que seriam sempre transacionadas caixas completas de produtos e que esta seria a linguagem comum a toda cadeia;

c) a partir da venda ao consumidor, o sistema é atualizado e ajusta o estoque; $\mathrm{e}$

d) necessidade de contagens periódicas para confrontar o estoque com o informado pelo sistema. No confronto sistema vs. real, apenas o gestor do restaurante consegue ajustar o estoque, justificando a razão do ajuste.

\subsubsection{Coleta de dados do restaurante e forma- ção do pedido}

Uma vez ajustado o estoque do restaurante e a venda extraída do registro no caixa, o sistema de informação cria um pedido recomendado ao restaurante. Ao mesmo tempo, o sistema gera também as informações aos agentes da cadeia para planejamento.

Numa segunda etapa, o sistema compõe os dados com outros fatores, como efeitos sazonais e promoções, para gerar o pedido sugerido. Nesta etapa, a intenção foi a de transformar as informações de venda da loja em pedido, utilizando-se para isso:

a) informação da quantidade da venda efetuada pelo restaurante, convertendo-a na linguagem da cadeia, isto é, caixas completas;

b) informação das variáveis que afetam o pedido como estoque do restaurante, influência de períodos históricos para a data em que se está prevendo a entrega do pedido e ações de marketing e promoções;

c) com base em todos os dados coletados e processados, o sistema gera ao restaurante um pedido recomendado, disponibilizado ao gerente no dia correto de se colocar o pedido. Para isso, utiliza um número básico para o ponto de reposição do estoque previamente definido entre os agentes; e

d) o restaurante confirma, ou altera a sugestão, para o pedido ser processado e entregue.

\subsubsection{Projeção de demanda}

Este é o fator de maior complexidade, pois se relaciona com inúmeras informações extraídas do passado, que são extrapoladas na intenção de melhorar as decisões do futuro, principalmente no que tange à produção e pedidos de compra.

A intenção era de fornecer ao supridor uma visão próxima do real, bem como dar a ele a visibilidade do que está acontecendo com seu produto no ponto-de-venda. Isto, por sua vez, permitiria um melhor planejamento do outro lado da cadeia, ou seja, no sentido montante.

Para isso, foram consideradas, no processo de cálculo, variáveis como o histórico de vendas do restaurante, promoções e fatores regionais que afetam a venda do restaurante. 


\subsubsection{Gestão das promoções e campanhas}

Nesta etapa, foram definidas as responsabilidades de quem alimenta o sistema com informações pertinentes à demanda, não se referindo a momentos sazonais, como período de festas ou feriados historicamente já conhecidos ou possíveis de levantamentos, mas sim, àquilo de novo que está sendo criado ou planejado e pode afetar os números.

No caso, a responsabilidade dessas informações foi atribuída aos gestores de marketing, que devem repassá-las ao PSL para que este alimente o sistema com os dados.

\subsubsection{Abastecimento do restaurante}

Tradicionalmente, a responsabilidade de colocar os pedidos para reposição do estoque era do gestor do restaurante que, por intermédio de uma série de análises e planilhas internas, colocava seus pedidos com base na receita dos produtos e na sua própria experiência. Esta tarefa, complexa e cercada de incertezas, passa a ser feita pelo sistema, ficando ao gestor o papel de aceitá-la ou não. No caso, o gestor abre a tela do pedido sugerido, analisa-o, altera-o, se necessário, e confirma o pedido. Caso não faça nada, o sistema acata o pedido sugerido.

\subsubsection{Gestão centralizada de pedidos}

No processo de implementação, foram definidas, também, as responsabilidades de cada participante no processo, como a do gestor do restaurante na gestão de estoque e colocação de pedidos e a dos gestores de marketing em administrar as campanhas e promoções. No entanto, todas essas atividades necessitavam de monitoramento para evitar distorções que afetem o processo. Isto é feito a partir de uma ampla visão do todo, a qual aponta se, pontualmente, algo não está ocorrendo como o previsto.

Essa função ficou concentrada no PSL, que passou a monitorar os dados históricos gerados pelo sistema, evitando incoerências. Por outro lado, acompanha a movimentação dos restaurantes, checando se, de fato, os gestores das lojas estão corrigindo e ajustando o estoque e se os inputs de cada área de influência estão ocorrendo ou não. Com isso, torna-se possível ao PSL visualizar todas as inconsistências, podendo este ter uma visão macro do processo.

As ações mencionadas referem-se a um resumo das etapas que foram sendo efetivadas à medida que o projeto se desenvolvia. A maioria das ações demandou grande processamento de dados, análises e testes, antes que se pudesse alcançar o modelo final.

\subsubsection{Medidas e indicadores}

$\mathrm{O}$ indicador de maior representatividade adotado pelo grupo foi o de "aceitação do pedido sugerido" - (APS) pelo restaurante. Seu cálculo advém da relação das quantidades sugeridas dos produtos pelas alterações feitas pelo gestor. Outros indicadores foram também definidos, como os apresentados a seguir.

a) giro de produtos: visa medir se o giro de estoque no restaurante é grande o suficiente para evitar perdas, problemas de shelf-life e, principalmente, estoque desnecessário;

b) desperdício: com base nos ajustes apontados pelo gestor do restaurante, bem como na diferença do sugerido pela receita dos produtos e o real realizado pelo restaurante, é possível ter o índice de desperdício do restaurante. Esse, por sua vez, quando melhor gerenciado, melhora diretamente o resultado do ponto-de-venda;

c) nível de confiabilidade do estoque (real vs. apontado pelo sistema): a intenção com este indicador é poder monitorar o comportamento do sistema, dos dados gerados e da ação dos gerentes no ponto-de-venda;

d) relação da venda informada por campanha com o real: para cada input de dados realizado pelos gestores de marketing, o sistema gera um comparativo na intenção de fornecer os subsídios necessários para correção e melhoria da previsão;

e) índice de cortes de produto por fornecedor (produto não entregue por falha do fornecedor): procura saber qual a proporção da falha no abastecimento gerado pelo fornecedor. É a relação entre o volume sugerido pelo sistema para abastecimento e o que deixou de ser atendido;

f) indicador de pedido previsto vs. real consumido no período: um indicador, por fornecedor e item, que compara o que efetivamente foi entregue aos restaurantes com o que foi previsto para o fornecedor; e

g) desempenho global da cadeia: o grupo não conseguiu estabelecer um consenso nem um método de como fazer isto. $\mathrm{O}$ indicador mais aceito foi a falta de produtos no restaurante por deficiência da cadeia, informação que o PSL tinha como apurar e disponibilizar a todos.

\subsection{Problemas e resultados na implementação do collaborative planning, forecasting, and replenishment}

Um projeto como esse é extremamente complexo, por envolver muitas empresas, diferentes sistemas de dados, e culturas administrativas e operacionais divergentes. Portanto, problemas e conflitos são pertinentes ao processo, alguns de maior complexidade, outros de menor. Neste estudo, a solução destes problemas e conflitos se reverte em resultados que a implementação de um CPFR proporciona aos agentes:

a) contribui para melhor definição do ponto de reposição de estoque: ao determinar a fórmula do ponto 
de reposição do estoque, variáveis como estoque inicial, transformação das vendas do cardápio em itens de estoque, como trabalhar com vendas do passado, desperdício, consumo do próprio restaurante, transferência de produtos, rendimento dos produtos e análise do histórico adotado como referência para os pedidos projetados, foram itens que precisaram ser trabalhados e estudados. O grupo estabeleceu alguns parâmetros com base em dados históricos, outros necessitaram decisões de consenso $\mathrm{e}$, à medida que os testes aconteciam, o sistema foi sendo corrigido;

b) ajuda a definir o rendimento dos produtos: havia divergências no rendimento dos ingredientes que era utilizado na receita do produto vendido pelo restaurante. Fabricantes e restaurantes não diziam a mesma coisa. Adotou-se um número baseado na prática dos restaurantes e um grupo especialmente formado com esta finalidade ficou de acompanhar o rendimento real para, paulatinamente, corrigir o sistema;

c) define regras para vendas esporádicas e limitadas: a questão aqui é como parametrizar o sistema para tratar as vendas de itens que são vendidos uma única vez e nunca mais voltam a ser vendidos, como é o caso de brindes periódicos. O sistema adota uma média sugerida por restaurante, segundo a sua venda histórica e, baseado no volume previsto da campanha, faz-se uma distribuição proporcional, ou seja, o restaurante que vende mais recebe proporcionalmente mais. Adota-se, também, uma distribuição proporcional para o período da campanha, ou seja, se for de quatro semanas, o restaurante recebe $40 \%$ na primeira semana (por causa do pico de venda e do fator novidade, por exemplo) e o restante nas três seguintes;

d) evita estoque negativo: devido a erros do sistema ou de apontamento por parte do restaurante, era comum o sistema informar "estoque negativo". Na intenção de melhorar a atenção e os processos, passou-se a divulgar os erros. Por outro lado, erros oriundos de formulação, ou mesmo de apontamento errado da receita, foram sendo corrigidos à medida que apareciam;

e) padronização de layout das telas de operação: a questão aqui se referiu a como se encontrar o layout ideal da tela de pedido projetado. Apesar do consenso inicial entre os participantes, à medida que se passou a operar o sistema, surgiram novas situações, as quais foram corrigidas na intenção de tornar o sistema mais amigável e fácil de acessar e trabalhar;

f) gera confiabilidade no sistema de informações: um aspecto complicador identificado refere-se a como garantir que os dados no sistema estão sendo transferidos de fato e se são, de fato, confiáveis. Considerando que a coordenação passou a ser feita pelo PSL, este montou um grupo de checagem para acompanhar, em cada ponto, se as informações eram confiáveis e coerentes com históricos e realidade;

g) melhora os pedidos de abastecimento do pontode-venda por haver melhor gerenciamento do estoque: antes do projeto, os gerentes dos restaurantes estavam acostumados a fazer seus pedidos com base apenas nas vendas e, periodicamente, ajustavam os estoques com base na posição física, o que, na prática, gerava grandes distorções ou faltas e sobras de produtos. Com o sistema informatizado, ter o estoque ajustado, em tempo real, em cada ponto-de-venda passou a ser fundamental para o acerto do pedido e para corrigir as informações de demanda;

h) aprimora as informações de campanha e promoções: a área de marketing, inicialmente, teve muita dificuldade para fornecer informações sobre projeções e impactos nas vendas devido a campanhas ou novos lançamentos. Apesar de trabalharem com previsões e perspectivas, adotá-las num sistema integrado parecia arriscado, uma vez que as informações ficariam expostas a erros e, claramente, isso seria percebido. A questão era muito mais cultural do que operacional. Até porque, presumia-se que esses dados seriam melhorados à medida que se aprendesse a operar o sistema;

i) ajuda na divulgação e informações sobre novos produtos: os dados relativos aos novos produtos não chegavam a tempo para se definir receita e rendimento e, conseqüentemente, o cadastro ficava incompleto. Foi adotado um valor base para estes dados e, nos primeiros dias de venda, as informações foram sendo corrigidas. Esta questão foi sendo trabalhada à medida que ocorria, na intenção de ter das áreas de desenvolvimento a receita correta antes do lançamento efetivamente;

j) define responsáveis pelo estoque de segurança: é o estoque necessário para suprir o consumo entre um recebimento e outro do pedido de compra. Assim, se um restaurante recebe de dois em dois dias, ele teria sempre um pedido à frente, ou seja, dois dias de consumo. A intenção era não deixá-lo sem produto em caso de um aumento expressivo de venda. Apesar da formulação do sistema adotar este mínimo e efetuar a sugestão, a gestão deste estoque fica exclusivamente a cargo do gerente do restaurante, podendo, caso considere conveniente, adotar apenas um dia e correr o risco de ficar sem produtos; 
k) elimina diversas inconsistências de informações: alguns dados e premissas não eram precisos, não refletindo a realidade. Isto acontecia com relativa freqüência, principalmente no início da implementação, como previsto por todos. À medida que se entendia a razão, as devidas correções foram sendo efetivadas. Entretanto, algumas questões ficaram para ser discutidas ou melhoradas posteriormente, $\mathrm{e}$ outras até mesmo ficaram sem solução. Um exemplo disso eram as projeções de dados e pedidos baseadas na previsão do tempo. Como não se tinha um histórico disso, tornou-se difícil adotar uma posição a respeito. Apenas se sabia que quando chovia vendia-se mais ou menos, por exemplo;

1) contribui para que não haja omissão de informações: os restaurantes omitiam informações entre eles, como empréstimos de produto, por exemplo. Isto se devia a um fator cultural, que precisaria ser corrigido, pois o gestor tinha em mente que o sistema iria apontar esta operação, por gerar inconsistências no estoque;

m) exige envolvimento dos participantes: puderam ser percebidas reações diferentes dos participantes às solicitações e necessidades. Enquanto alguns se mostraram muito empenhados, outros não se envolveram muito. Uma das razões estava no fato de que, exceto o PSL, os demais dividiram as atividades aos profissionais que continuavam com as mesmas responsabilidades anteriormente. Isto, muito provavelmente, impactava na dedicação. Algumas não evoluíam, provavelmente pelo fato de estarem com dedicação mais focada na operação do dia-a-dia e não no projeto; e

n) define regra para o consumo de itens genéricos: um grande desafio foi lidar com itens de consumo genérico, indiretos, como guardanapos, canudos, sal em sachet, etc., que não têm receita definida. Isto gerou muita dificuldade em se estabelecer uma linha de abastecimento, pois o consumo nos restaurantes é livre e não existe receita para eles. O procedimento adotado foi estabelecer uma relação entre as vendas e o consumo de cada um, sendo que, em caso de distorções ocorridas em um ponto-de-venda, o gestor deveria corrigi-lo.

Muitos foram os obstáculos surgidos durante o desenvolvimento do processo de implementação do CPFR, alguns com impacto direto na continuidade das etapas, outros inerentes ao sistema de gestão ou relacionados às tarefas. No entanto, todos aqueles obstáculos que comprometem a qualidade final da informação foram considerados como mais críticos, uma vez que a informação é o elemento principal do sistema. Por outro lado, a resolução de cada obstáculo gera resultados para os agentes, conseqüentemente para a cadeia.

\section{Redefinição do papel dos agentes da cadeia de suprimentos}

O desenvolvimento dos ciclos de trabalhos, com visão exclusiva nas atividades e processos que necessitariam de melhorias ou ainda não existiam, demonstra certo grau de desenvolvimento e foco colaborativo nas relações entre os agentes da CS. Essa característica se apóia no histórico da própria rede de fast-food, bem como pelo estilo de administração adotado com seus fornecedores, no qual o processo de cooperação parece estar presente.

A Figura 3 ilustra as três grandes etapas (e seus propósitos) do projeto relatado neste artigo e que podem orientar outras empresas em projetos de implementação de CPFR.

Um aspecto importante identificado é o fato do sistema logístico, coordenado pelo PSL, ter forte presença na SCM, possibilitando à rede de fast-food confiar a ele o processo de implementação. Por outro lado, um fator que muito contribui para isso é o PSL estar bem estruturado tecnologicamente para a gestão de informações. Neste sentido, ficou definido o seguinte papel para cada um dos principais agentes da cadeia.

\subsection{Empresa foco}

Como idealizadora do projeto, trabalha no convencimento dos agentes da importância e das possibilidades de ganho a todos. Valida o processo e apóia o PSL em todas as ações de coordenação e implementação. Tem papel fundamental, ao estimular a relação e a busca de soluções para os diferentes problemas que surgem, tomando as decisões e definindo o caminho quando surgem impasses. Tem papel atuante no processo de implementação com:

a) Fornecedores

Negocia com os fornecedores a respeito de quem participa do processo de integração total (on-line, em tempo real) ou parcial (via internet) do sistema de informação.

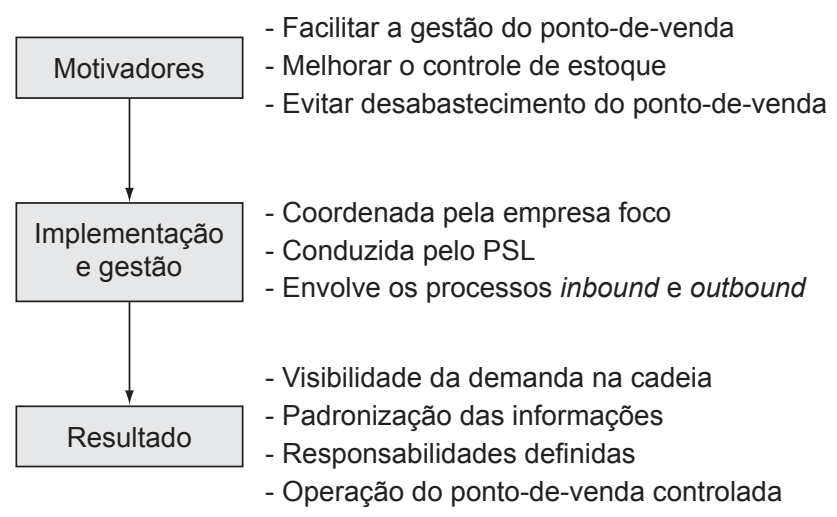

Figura 3. Principais etapas do projeto de implementação do CPFR. 
Trabalha na definição de unidades de venda e codificação dos produtos.

Define estratégia de volume de estoque com cada fornecedor, repassando esta orientação para o monitoramento do PSL.

b) Restaurantes

Define os restaurantes e as praças que serão integradas no projeto.

Orienta os gestores dos restaurantes quanto às práticas e padrões que serão estabelecidos no projeto.

Valida os impactos de promoção e campanhas.

Permite o acesso aos sistemas dos restaurantes para coleta de dados.

\subsection{Fornecedores}

São três as categorias de fornecedores envolvidos no projeto. Uma é a primária, que atua, praticamente, com exclusividade para a rede de fast-food; outra é a secundária, que tem outros negócios e clientes, mas o volume é extremamente representativo e interessante como negócio para empresa; a terceira atende outros clientes e não fornece volumes representativos, mas reconhece que ter a rede de fast food como cliente é importante. Desta forma, consegue-se ter a participação de todos, alguns mais focados nos sistemas de integração, outros relativamente livres, mas com todas as informações necessárias para alimentar o sistema. Pode-se definir o papel dos fornecedores no projeto e no processo de CPFR como sendo o de:

a) Acessar todas as informações de estoque, pedidos e previsões no PSL para seus produtos;

b) Visualizar a venda real de seus produtos no ponto-de-venda (consolidada, por região ou por ponto-de-venda); e

c) Disponibilizar ou transmitir informações sobre seus estoques ao PSL.

\subsection{O prestador de serviços logísticos}

Agente integrador no processo tem no relacionamento o ponto forte de sua gestão, pois precisa conduzir diversos agentes e diferentes interesses. Por ser o coordenador das ações e ter força dedicada ao projeto, o PSL assume a responsabilidade de trabalhar para que as ações planejadas se concretizem. Assume também o processo de integração entre os sistemas de informação, trabalhando na construção das interfaces entre os diversos agentes. Alimenta a rede de fast-food com informações sobre como estão os agentes e quais precisam de ajuda para corrigir e aperfeiçoar o projeto. Assim, o PSL assume as seguintes finalidades:

a) Integrar os agentes, construindo e coordenando os portais e as interfaces entre as empresas; b) Manter a coordenação do projeto mediante gestão exclusiva e dedicada, podendo, por ter ampla visão do processo, orientar todos os agentes participantes, bem como gerar todas as informações necessárias ao sistema; e

c) Manter ou mesmo obter a tecnologia necessária para gerar o banco de dados e o sistema de coleta e transmissão de informações.

\section{Considerações finais}

Um projeto como este é bastante amplo, repleto de variáveis e de situações capazes de gerar muitos outros trabalhos acadêmicos. No entanto, o foco dos autores foi analisar o processo de implementação de um CPFR numa CS colaborativa, com a gestão a cargo da empresa foco, porém, coordenado pelo PSL.

Esta particularidade, a de um PSL poder coordenar um processo colaborativo na cadeia, principalmente de tamanha complexidade como um CPFR, traz interessantes contribuições para estudos na área, ou mesmo para empresas que pensam em utilizar esta prática. Além disso, pode-se atribuir o fato de se chegar ao final do projetopiloto com 15 restaurantes operando de acordo com o sistema CPFR, pela coordenação e iniciativa do PSL em administrar todas as interfaces com os participantes.

Outro dado interessante do estudo foi que, no final do projeto, o índice de aceitação dos pedidos sugeridos estava em $76 \%$, dentro da média de índices citados na literatura para projetos deste tipo (HOLMSTROM et al., 2002).

Apesar de algumas etapas ou situações apresentadas neste estudo poderem ser generalizadas para outros tipos de cadeias de suprimentos, o estudo é limitado a um caso específico e a abrangência de qualquer conceito ou experiência citada deve ser estudada de forma mais ampla. Outras questões que podem ser mais bem exploradas em estudos futuros referem-se ao papel do PSL em processos de integração da CS, bem como, ao fato dos relacionamentos da cadeia não se restringirem apenas aos fornecedores de primeira camada. Também, questões relativas à definição de indicadores de desempenho da cadeia como um todo precisam ser mais bem estudadas.

Considerando tão somente este caso, uma análise mais profunda dos aspectos que favoreceram a implementação e dos processos já existentes entre os agentes, contribuiria ainda mais para o entendimento do tema. Esta é uma das diversas oportunidades que os autores têm de explorar ainda mais este caso.

Entretanto, independentemente das limitações do estudo e de sua proposta, pode-se realçar pontos interessantes em termos de CS colaborativas, como a possibilidade da utilização de PSLs na coordenação de parte deste trabalho. Do lado dos PSLs, ressalta-se a 
importância deles estarem atentos às novas práticas colaborativas e se prepararem com sistemas que permitam oferecer serviços desse porte.

No processo de implementação, a maturidade da cadeia, devidamente coordenada pela empresa foco, com fornecedores bem definidos e integrados ao negócio, ajuda e facilita o processo. Portanto, antes de se desejar uma integração nos moldes do CPFR, as etapas que consolidem o relacionamento e permitam aos participantes da cadeia entender seu papel devem ser superadas.

Mesmo em uma cadeia em que o relacionamento esteja maduro, haverá muitos problemas e dificuldades, principalmente quando envolvem interesses dos participantes. Um conflito difícil de prever e resolver refere-se à ocorrência de eventuais erros nos pedidos recomendados. É de fundamental relevância que os gestores da empresa foco da cadeia se envolvam no processo como parte do grupo, evitando estar na posição de apenas ser servido.

Outro aspecto de destaque no estudo foi que a participação de pessoas dedicadas ao projeto de implantação mostrou-se fundamental para a melhoria dos resultados. Não possuir responsáveis dedicados num projeto como este, que exige muitas informações, análises e correções, pode comprometer etapas do trabalho. Portanto, acredita-se que os gestores devam se envolver e ter responsabilidades sobre os processos, porém, devam ter também o apoio de pessoas que manipulam dados e informações, pois são esses dados e informações que irão sustentar a credibilidade das decisões.

A definição clara das rotinas nos diversos pontos da cadeia é crucial para a operacionalização do CPFR. Dentre estas rotinas, podem ser citadas aquelas relativas à integração dos fornecedores com as informações no sistema; a dos restaurantes em acompanhar as sugestões e, principalmente, fazer a gestão de estoque; a do PSL em garantir a transmissão de dados e checagens necessárias para não haver falhas; e a da empresa foco em fornecer os dados, principalmente de campanhas e informações.

Por outro lado, um processo como este, fundamentalmente, se apóia na tecnologia da informação e comunicação. Assim, é primordial estar apoiado num sistema de dados robusto, com processamento ágil e seguro, capaz de trabalhar com todas as interfaces necessárias.

\title{
Implementation of a Collaborative Planning, Forecasting, and Replenishment system in a large fast food company through a logistics provider
}

\begin{abstract}
Nowadays, Collaborative Planning has been considered a key element in the Supply Chain Management context. In this article, this topic is addressed by a real case where a large worldwide fast-food network and its logistics provider worked together in Brazil in a pilot project in order to implement a Collaborative Planning, Forecasting, and Replenishment (CPFR) system. Based on an action research approach, this paper presents the main variables that influenced the real project embracing the necessary processes, and it points out those that leveraged the CPFR implementation. Based on the case studied, a set of proposals about the role of the supply chain agents in similar projects is presented. Moreover, the case of conducting the supply chain management by a direct coordination of a logistics provider also allows to highlight the possibilities and difficulties of the CPFR system and to contribute towards a supply chain agents collaborative work.
\end{abstract}

Keywords: Supply chain management. Collaborative planning. Forecasting and replenishment (CPFR). Logistic provider. 
BONET, D.; PACHÉ, G. A. New Approach for Understanding Hindrances to Collaborative Practices in the Logistics Channel. International Journal of Retail \& Distribution Management, v. 33, n. 8, p. 583-596, 2005.

CHRISTOPHER, M.; TOWILL, D. An integrated model for the design of agile supply chains. International Journal of Physical Distribution \& Logistics Management, v. 31, n. 4, p. 235-246, 2001.

COUGHLAN, P.; COGHLAN, D. Action research for operations management. International Journal of Operations \& Production Management, v. 22, n. 2, p. 220-240, 2002.

DANESE, P.; ROMANO. P.; VINELLI, A. Managing business processes across supply networks: the role of coordination mechanisms. Journal of Purchasing and Supply Management, n. 10, p. 165-177, 2004.

DISNEY, S. M.; TOWILL, D. R. Vendor-Managed Inventory and Bullwhip Reduction in a Two level Supply Chain. International Journal of Operation \& Production Management, v.23, n. 6, p. 625-651, 2003.

DISNEY, S. M.; POTTER A. T.; GARDNER, B. M. The Impact of Vendor Managed Inventory on Transport Operations. Transportation Research part E, v. 39, p. 363-380, 2003.

FLIEDNER, G. CPFR: an emerging supply chain tool. Industrial Management \& Data Systems, v. 103, n. 1, p. 14-21, 2003.

GOLIC, S. L.; MENTZER, J. T. An Empirical Examination of Relationship Magnitude. Journal of Business Logistics, v. 27 , n. 1, p. 81, 2006.

HARRISON, A.; HOEK, V. R. Logistics Management and Strategy. London: Financial Times/Prentice-Hall, 2002.

HOLMSTROM, J.; FRAMLING, K.; KAIPIA, R. S. Collaborative planning forecasting and replenishment: new solutions needed for mass collaboration. Supply Chain Management: An International Journal, v.7, n.3, p. 136-145, 2002.

LIEB, R.; BENTZ, B. A. The use of third-party Logistics Services by large American manufactures: the 2004 survey. Transportation Journal, v. 44, n. 2, 2005.

MENTZER, J. T.; MOON, M. A. Understanding Demand. Supply Chain Management Review, v. 8, n. 4, p. 38, may/jun. 2004.

MIN, S. et al. Supply Chain Collaboration: What's happening? The International Journal of Logistics Management, v. 16, n. 2, p. 237-256, 2005.

OVALLE, O. R.; MARQUEZ, A. C. The effectiveness of using e-collaboration tools in the supply chain: an assessment study with system dynamics. Journal of Purchasing \& Supply Management, v. 9, p. 151-163, 2003.

PIRES, S. R. I. Gestão da Cadeia de Suprimentos - Conceitos, Estratégias, Práticas e Casos. São Paulo: Editora Atlas, 2004.

PORIER, C. C.; QUINN, F. J. The Third Annual Global Survey of Supply Chain Progress. Supply Chain Management Review, January, 2006.

SAHAY, B. S. Supply chain collaboration: The key to value creation. Work Study, v. 52, n. 1, p. 76-83, 2003.

SKJOETT-LARSEN, T.; THERNOE, C.; ANDERSEN, C. Supply chain collaboration: theoretical perspectives and empirical evidence. International Journal of Physical Distribution \& Logistics Management, v. 33, n. 6, p. 531-549, 2003.

VICS (Voluntary Interindustry commerce standards). Collaborative planning, forecasting and replenishment. Voluntary Guidelines. Disponível em http://www.cpfr.org. Acesso em: 28 de abril de 2004.

WANKE, P. F.; ZINN, W. Strategic Logistics Decision Making. International Journal of Physical Distribution \& Logistics Management, v. 34, n. 6, p. 466-478, 2004.

\section{Sobre os autores}

\section{Mauro Vivaldini}

Universidade Metodista de Piracicaba (UNIMEP),

Rod. Sta Bárbara/Iracemápolis, Km 1, CEP 13450-000, Sta. Bárbara D’Oeste, SP, Brasil,

e-mail: mvivaldini@mbbrasil.com.br

\section{Fernando Bernardi de Souza}

Universidade Estadual Paulista (UNESP),

Av. Eng. Luiz Edmundo Couba 14-01, CEP 17033-360, Bauru, SP, Brasil,

e-mail: fbernardi@feb.unesp.br

\section{Silvio Roberto Ignácio Pires}

Universidade Metodista de Piracicaba (UNIMEP),

Rod. Do Açúcar, Km 156, CEP 13400-911, Piracicaba, SP, Brasil,

e-mail: sripires@unimep.br 